\title{
A prospective study of asthma incidence and its predictors: the RHINE study
}

\author{
K. Torén*\#, T. Gislason ${ }^{\top}$, E. Omenaas ${ }^{+}$, R. Jögi ${ }^{\S}$, B. Forsberg ${ }^{f}$, L. Nyström ${ }^{f}$, A-C. Olin*, C. Svanes ${ }^{+}$, \\ C. Janson**, on behalf of the RHINE study group
}

A prospective study of asthma incidence and its predictors: the RHINE study. K. Torén, T. Gislason, E. Omenaas, R. Jögi, B. Forsberg, L. Nyström, A-C. Olin, C. Svanes, C. Janson, on behalf of the RHINE study group. (C) ERS Journals Ltd 2004. ABSTRACT: The objective of this longitudinal study was to estimate the incidence rate of asthma, and to compare the incidence between subjects with or without baseline reporting of certain respiratory symptoms.

A follow-up of the random population samples in the European Respiratory Health Survey (ECRHS) in Sweden, Norway, Denmark, Iceland and Estonia was conducted in 1999-2001, in a population aged 30-54 yrs at follow-up $(n=14,731)$. Asthma was defined as reporting either asthma or physician-diagnosed asthma, and a reported year when asthma symptoms were first noticed. Incidence rates, incidence rate ratios and hazard ratios were calculated with $95 \%$ confidence intervals.

The incidence rate of asthma was 2.2 cases per 1,000 person-yrs. The incidence was higher among females $\left(2.9\right.$ cases $\cdot 1,000$ person-yrs $\left.{ }^{-1}\right)$ than among males $(1.5$ cases $\cdot 1,000$ person-yrs ${ }^{-1}$ ). When subjects with baseline reporting of wheezing were excluded, the incidence rate decreased to 1.7 cases $\cdot 1,000$ person-yrs ${ }^{-1}$, with a further decrease to 1.5 cases 1,000 person-yrs ${ }^{-1}$ after exclusion of subjects with wheezing, nocturnal dyspnoea, chest tightness and cough. There was a strong association between onset of asthma and wheezing at baseline.

In this prospective, population-based study, the incidence rate of asthma in the whole population sample ranged $1.5-2.2 \cdot 1,000$ person-yrs ${ }^{-1}$, with a higher incidence range among females. The incidence was dependent on the extent to which subjects with respiratory symptoms were excluded from follow-up. Hence, for comparability between studies, the exclusion criteria in the follow-up population must be stated.

Eur Respir J 2004; 24: 942-946.
Depts of * Occupational and Environmental Medicine, and \# Respiratory Medicine and Allergology, Sahlgrenska University Hospital, Göteborg, ** Dept of Medical Sciences, Respiratory Medicine and Allergology, Uppsala University, Uppsala, ${ }^{\circ}$ Depts of Public Health and Clinical Medicine, Epidemiology, Umeå University, Umeå, Sweden. "Dept of Pulmonary Medicine, Landspitali University Hospital, Reykjavik, Iceland. ${ }^{+}$Dept of Thoracic Medicine and Centre for Clinical Research, Haukeland University Hospital, Bergen, Norway. ${ }^{\$}$ Foundation Tartu University Clinics, Lung Clinic, Tartu, Estonia.

Correspondence: K. Torén, Dept of Occupational and Environmental Medicine, S:t Sigfridsgatan 85B, S-412 66 Göteborg, Sweden. Fax: 46 31409728. E-mail: Kjell.Toren@ymk gu.se

Keywords: Epidemiological studies, longitudinal studies, lung diseases, obstructive

Received: April 162004

Accepted after revision: August 92004

This study was supported by the Swedish Council for Worklife Research (FAS); Herman Kreftings Fund for Asthma Research; Torsten and Ragnar Söderberghs Medical Foundation; the Swedish Heart and Lung Foundation; the Norwegian Asthma and Allergy Research Fund; and the Icelandic Research Council.
There have been few studies of asthma incidence among adults. The diagnostic criteria for new-onset asthma have been based on either clinical investigations, or self-reported asthma or physician-diagnosed asthma [1, 2]. Reports on asthma are more common and, over the last $10 \mathrm{yrs}$, questionnaire-based incidence studies have been published in the USA, Scandinavia, Spain and Italy, showing incidence rates from $1-5$ cases per 1,000 person-yrs ${ }^{-1}$ [3-9].

It is difficult to decide which subjects should be excluded from the baseline population in a prospective study of asthma incidence. One key question to consider is: when does a symptomatic condition present at baseline cross over to be included in the definition of asthma? More precisely, should subjects reporting wheezing or other asthma-associated symptoms (but not asthma) at baseline be considered as a group with increased risk for asthma onset or should they be excluded because they probably already have asthma?

The observed incidence rate at follow-up is also dependent on the extent to which symptomatic subjects are misclassified as healthy and, hence, are included in the baseline population [10]. This may be one reason for the varying estimates of incidence that have been published. One way to decrease this bias is to widely exclude subjects who report respiratory symptoms at the start of follow-up.
In a prospective study from Spain, BASAGANA et al. [6] observed that the incidence rate decreased from 3.3 to $2.8 \cdot 1,000$ patient-yrs when subjects reporting asthma attacks, use of asthma medications and attacks of nocturnal dyspnoea at start of follow-up were excluded. The incidence rate further decreased to $2.0 \cdot 1,000$ patient-yrs when, in addition, subjects reporting wheezing, nocturnal chest tightness or nocturnal coughing were also excluded.

Here, a large prospective study of the incidence rate of asthma among adults from five countries in northern Europe (Sweden, Denmark, Norway, Iceland and Estonia) is presented, with the aim of estimating the incidence rate of adult-onset asthma, and its relation to allergic rhinitis and respiratory symptoms assessed at the start of follow-up. The effect on the estimated incidence rate due to different exclusion criteria at the start of follow-up is also analysed.

\section{Methods}

The population of the study were subjects $(n=21,802)$ born between 1945 and 1973, who participated in stage 1 of the European Community Respiratory Health Survey (ECRHS 
I), 1989-1992 [11], from: Reykjavik in Iceland; Bergen in Norway; Umeå, Uppsala and Göteborg in Sweden; Aarhus in Denmark; and Tartu in Estonia. In 1999-2001, at follow-up, the eligible subjects were mailed a questionnaire, of which $16,191(74 \%)$ answered.

In the first survey, subjects answered the ECRHS screening questionnaire, comprising items about wheezing, nocturnal chest tightness, nocturnal dyspnoea, nocturnal cough, attacks of asthma during the last 12 months, current use of asthma medication and allergic rhinitis.

At follow-up the subjects were investigated with another questionnaire, the first part of which contained questions identical to those previously used [11]. The second part included items about self-reported asthma.

Incident asthma was defined as a positive answer to either "Do you have or have you ever had asthma?" or "Have you ever had asthma diagnosed by a doctor?", and a reported year for onset of asthma symptoms [1].

Allergic rhinitis was defined as a positive answer to "Do you have any nasal allergies including hay fever?".

Never-smoking person-years were defined from the start of follow-up until the end of the observation period (if the person did not start to smoke). If the person smoked at the start of follow-up then smoking person-years were defined from the start of follow-up until smoke-stop or until the end of the observation period. If the person started to smoke during the follow-up period, smoking person-years were counted from smoke-start until smoke-stop or until the end of the observation period. Ex-smoking person-years were counted from the first year after smoke-stop until the year of follow-up. Smoking history at the end of follow-up was categorised as never-smoker, ex-smoker, current smoker or unknown.

Subjects reporting asthma onset before or at the year of first survey were excluded, as well as subjects reporting asthma attacks or use of asthma medication at the start of follow-up, resulting in a study population at risk of 14,731 subjects (tables 1 and 2).

Table 1. - Prevalence of respiratory symptoms (at baseline) in a prospective study of 14,731 subjects from northern Europe

Symptom at baseline Responders $n$ Prevalence affirmative answers $\%$

\begin{tabular}{llr}
\hline Wheezing & 14586 & 17.3 \\
Nocturnal chest tightness & 12250 & 7.3 \\
Nocturnal dyspnoea & 14653 & 3.5 \\
Nocturnal cough & 14638 & 25.8 \\
Allergic rhinitis & 14566 & 16.0 \\
\hline
\end{tabular}

All subjects did not answer to all items.

Table 2. - Age, sex, smoking habits and cumulative incidence of asthma at follow-up in a prospective study of 14,731 subjects from northern Europe

\begin{tabular}{lc}
\hline All subjects n & 14731 \\
Age mean \pm SD & $39.8 \pm 7.3$ \\
Males & $6979(47.4)$ \\
Never smokers & $6586(44.7)$ \\
Former smokers & $3615(24.5)$ \\
Current smokers & $4266(29.0)$ \\
Unknown smoking habits & $264(1.8)$ \\
New-onset asthma & $316(2.1)$
\end{tabular}

Data are presented as $\mathrm{n}(\%)$ unless otherwise stated.

\section{Statistical analyses}

Incidence rates were calculated as the number of new cases of asthma divided by the person-years at risk during the observation period. When asthma occurred, the subject ceased to contribute person-years. Incidence rates were calculated and 95\% confidence intervals (CI) have been outlined assuming a Poisson distribution [12]. Incidence rate ratios (IRR) were calculated according to Mantel-Haenszel and odds ratios (OR) were calculated with logistic regression models. All p-values are two-sided, and they are based on a Chi-squared test for categorical variables and on a t-test for continuous variables. The homogeneity between centres regarding incidence rates of asthma was tested according to RothMAN and GREENLAND [13].

Cox regression analyses were performed with person-years under observation as the dependent variable and asthma as an event, stratified for centre. Hazard ratios (HR) are given for explanatory variables, included simultaneously in the model, as well as smoking time, sex and age.

\section{Results}

With all centres merged, 316 new cases of asthma occurred during the observation period 1989-2001, based on 141,200 person-years under observation. The cumulative incidence for the whole period was $2.1 \%$. The crude incidence rate was 2.2 cases $\cdot 1,000$ person-yrs ${ }^{-1}(95 \%$ CI $1.8-2.8)$. The incidence was higher $(\mathrm{p}<0.05)$ among females $\left(2.9\right.$ cases $\cdot 1,000$ person-yrs $\left.{ }^{-1}\right)$ than among males (1.5 cases 1,000 person-yrs $\left.{ }^{-1}\right)$. The incidence was similar among those born in 1960-1973 and those born in 1945-1959 (2.4 versus 2.1 cases 1 ,000 person$\left.\mathrm{yrs}^{-1} ; \mathrm{p}>0.05\right)$. The incidence rate during never-smoking time was 1.8 cases $\cdot 1,000$ person-yrs ${ }^{-1}$, during ex-smoking time it was 2.1 cases $\cdot 1,000$ person-yrs ${ }^{-1}$ and during smoking time it was 2.4 cases 1,000 person-yrs ${ }^{-1}$. IRR (smoking/never-smoking) was 1.3 cases $\cdot 1,000$ person-yrs ${ }^{-1}(95 \%$ CI 1.01-1.6) and IRR (exsmoking/never-smoking) was 1.2 (95\% CI $0.9-1.5)$. In the univariate analyses, subjects reporting allergic rhinitis, respiratory symptoms (nocturnal cough, dyspnoea, or chest tightness or wheezing) had an increased incidence of asthma compared with those not reporting the symptoms (table 3 ).

Table 3. - Incident cases of asthma, incidence rates (cases per 1,000 person-yrs ${ }^{-1}$ under observation), incidence rate ratios (IRR) and 95\% confidence intervals (Cl) in 1989-2001, in relation to wheezing, nocturnal chest tightness, nocturnal dyspnoea, nocturnal cough and allergic rhinitis at start of follow-up

\begin{tabular}{lcccc}
\hline $\begin{array}{l}\text { Symptom at start } \\
\text { of follow-up }\end{array}$ & Cases $n$ & $\begin{array}{c}\text { Incidence } \\
\text { rate }\end{array}$ & IRR & $95 \%$ CI \\
\hline $\begin{array}{l}\text { Wheezing } \\
\quad \text { Yes }\end{array}$ & 112 & 4.8 & 2.8 & $2.3-3.3$ \\
$\quad$ No & 201 & 1.7 & & \\
$\quad \begin{array}{l}\text { Nocturnal chest tightness } \\
\quad \text { Yes }\end{array}$ & 49 & 4.9 & 2.3 & $1.8-3.0$ \\
$\quad$ No & 228 & 2.1 & & \\
$\quad$ Nocturnal dyspnoea & 21 & 4.4 & 2.1 & $1.4-3.1$ \\
$\quad$ Yes & 292 & 2.2 & & \\
$\quad$ No & 124 & 3.5 & 2.0 & $1.7-2.3$ \\
Nocturnal cough & 187 & 1.8 & & \\
$\quad$ Yes & & & & \\
$\quad$ No & 99 & 4.9 & 2.5 & $2.0-3.0$ \\
Allergic rhinitis & 210 & 1.8 & & \\
$\quad$ Yes & & & & \\
$\quad$ No &
\end{tabular}


Table 4.- Incidence rates of asthma (cases per 1,000 person-years under observation) in 1989-2001 in relation to respiratory symptoms at start of follow-up

\begin{tabular}{|c|c|c|c|c|}
\hline \multirow[t]{2}{*}{ Symptom at start of follow-up } & \multicolumn{4}{|c|}{ Exclusion criteria } \\
\hline & Wheezing & $\begin{array}{l}\text { Wheezing or } \\
\text { nocturnal dyspnoea }\end{array}$ & $\begin{array}{c}\text { Wheezing, nocturnal } \\
\text { dyspnoea or chest tightness }\end{array}$ & $\begin{array}{l}\text { Wheezing, nocturnal dyspnoea, } \\
\text { chest tightness or cough }\end{array}$ \\
\hline \multicolumn{5}{|l|}{ Nocturnal dyspnoea } \\
\hline Yes & $5.0(2.7-8.5)$ & & & \\
\hline No & $1.7(1.4-1.9)$ & & & \\
\hline \multicolumn{5}{|l|}{ Nocturnal chest tightness } \\
\hline Yes & $3.5(2.1-5.5)$ & $2.2(1.0-4.1)$ & & \\
\hline No & $1.7(1.4-1.9)$ & $1.7(1.5-2.0)$ & & \\
\hline \multicolumn{5}{|l|}{ Nocturnal cough } \\
\hline Yes & $2.6(2.0-3.3)$ & $2.4(1.8-3.1)$ & $2.3(1.7-3.1)$ & \\
\hline No & $1.5(1.3-1.7)$ & $1.5(1.3-1.7)$ & $1.5(1.0-2.0)$ & \\
\hline \multicolumn{5}{|l|}{ Allergic rhinitis } \\
\hline Yes & $3.8(2.9-4.8)$ & $3.7(2.9-4.8)$ & $3.7(2.8-4.7)$ & $3.4(2.5-4.7)$ \\
\hline No & $1.4(0.95-1.9)$ & $1.3(0.88-1.8)$ & $1.3(0.93-1.8)$ & $1.2(0.94-1.4)$ \\
\hline All & $1.7(1.5-2.0)$ & $1.7(1.5-2.0)$ & $1.6(1.2-2.2)$ & $1.5(1.0-2.0)$ \\
\hline
\end{tabular}

Data are presented as incident rate ratio $(95 \%$ confidence interval $(\mathrm{CI})$ ).

The highest risk estimate was among those reporting wheezing at the start of follow-up.

When subjects with respiratory symptoms were step-wise excluded from the follow-up population, the estimated incidence decreased from 2.2 to $1.5 \cdot 1,000$ patient-yrs (table 4). The univariate analyses, with regard to age, sex and smoking, were also performed after exclusion of subjects with wheezing, nocturnal dyspnoea, chest tightness and cough. The incidence was still higher $(\mathrm{p}<0.05)$ among females ( 1.9 cases $\cdot 1,000$ person-yrs $\left.{ }^{-1}\right)$ than in males $(1.0$ cases $\cdot 1,000$ person-yrs $\left.{ }^{-1}\right)$. The incidence was similar among those born in 1960-1973 and those born in 1945-1959 (1.7 versus 1.3 cases $\cdot 1,000$ person-yrs $\left.{ }^{-1} ; \mathrm{p}>0.05\right)$. The incidence rate during never-smoking time was 1.3 cases $\cdot 1,000$ person-yrs ${ }^{-1}$, during ex-smoking time it was 1.8 cases 1,000 person-yrs ${ }^{-1}$ and during smoking time it was 1.7 cases $\cdot 1,000$ person-yrs ${ }^{-1}$. IRR (smoking/never-smoking) was 1.3 (95\% CI 1.03-1.6) and IRR (ex-smoking/never-smoking) was 1.4 (95\% CI 0.97-2.0).

The Cox regression model, with all predictors in the same model, showed an increased HR for females (HR 1.9, 95\% CI 1.5-2.4). Reporting of wheezing and nocturnal cough as well as allergic rhinitis were associated with an increased risk for new-onset asthma (table 5). When all subjects reporting wheezing, nocturnal dyspnoea, chest tightness and cough at the start of follow-up were excluded, the risk for asthma among those with allergic rhinitis further increased.

In table 6 , the results from different centres are presented. The highest incidence rate was observed in Iceland (3.6 1,000 patient-yrs $^{-1}$, 95\% CI 3.0-4.9) and the lowest in Estonia $\left(0.5 \cdot 1,000\right.$ patient-yrs ${ }^{-1}, 95 \%$ CI $\left.0.2-1.1\right)$. The homogeneity test was not significant ( $>>0.2$, Chi-squared=3.1), meaning that the test did not detect heterogeneity between centres. When all subjects reporting wheezing, nocturnal dyspnoea, chest tightness and cough at the start of follow-up were excluded, the estimated incidences decreased, but the differences between centres remained. The fraction of incident cases with current asthma symptoms (at time of follow-up) was $60 \%$ in Iceland and $100 \%$ in Estonia. The fraction was $74 \%$ in Aarhus, $71 \%$ in Bergen, $79 \%$ in Göteborg, $84 \%$ in Umeå and $79 \%$ in Uppsala.

Compared with all responders $(n=16,191)$, the nonresponders $(n=5,611)$ were younger at the start of follow-up $(30.8$ versus 31.9 yrs, $\mathrm{p}<0.0001)$ and had higher prevalence of wheezing ( 24.1 versus $21.5 \%, \mathrm{p}<0.0001$ ), nocturnal symptoms (16.1 versus $13.9 \%, \mathrm{p}=0.0003)$ and allergic rhinitis (19.8 versus $18.0 \%, \mathrm{p}=0.003)$. The nonresponders were more often males (53.4 versus $46.6 \%, p=0.0004)$. No significant difference was found between nonresponders and responders regarding reported asthma attacks $(3.0$ versus $2.8 \%, \mathrm{p}=0.40)$ or use of asthma medication (3.7 versus $3.5 \%, \mathrm{p}=0.32$ ).

\section{Discussion}

The estimated incidence rate of self-reported asthma in this large prospective study was 2.2 cases 1,000 person-yrs ${ }^{-1}$ during the period 1989-2001, based on a prospective followup of a population with exclusion of subjects with asthma

Table 5. - Hazard ratios (HR) for onset of asthma in 1989-2001 in relation to sex, respiratory symptoms and allergic rhinitis at start of follow-up

\begin{tabular}{|c|c|c|c|c|}
\hline Baseline predictor & All subjects & $\begin{array}{c}\text { Subjects with } \\
\text { wheezing excluded }\end{array}$ & $\begin{array}{c}\text { Subjects with wheezing } \\
\text { or nocturnal dyspnoea excluded }\end{array}$ & $\begin{array}{l}\text { Subjects with wheezing, } \\
\text { nocturnal dyspnoea, chest } \\
\text { tightness and cough excluded }\end{array}$ \\
\hline Females & $1.9(1.5-2.4)$ & $1.8(1.3-2.5)$ & $1.9(1.4-2.6)$ & $1.8(1.4-2.6)$ \\
\hline Wheezing & $2.1(1.6-2.7)$ & & & \\
\hline Nocturnal dyspnoea & $1.4(0.8-2.4)$ & $2.7(1.4-5.3)$ & & \\
\hline Nocturnal chest tightness & $1.3(0.9-1.9)$ & $1.4(0.8-2.4)$ & $1.1(0.6-2.0)$ & \\
\hline Nocturnal cough & $1.4(1.1-1.8)$ & $1.4(1.01-1.9)$ & $1.4(0.99-1.97)$ & \\
\hline Allergic rhinitis & $2.3(1.8-3.0)$ & $2.7(2.0-3.6)$ & $3.0(2.2-4.0)$ & $2.9(2.1-3.9)$ \\
\hline
\end{tabular}

Data are presented as HR $(95 \%$ confidence interval $(\mathrm{CI}))$. Based on a Cox regression model adjusted for centre, smoking, age and sex, with simultaneous inclusion of all predictors. 
Table 6. - Incidence rates of asthma (cases per 1,000 personyears under observation) in 1989-2001, divided into different centres

\begin{tabular}{|c|c|c|}
\hline $\begin{array}{l}\text { Centre (period } \\
\text { of follow-up) }\end{array}$ & All subjects & $\begin{array}{l}\text { Subjects with wheezing, } \\
\text { nocturnal dyspnoea, } \\
\text { chest tightness and cough } \\
\text { at baseline excluded }\end{array}$ \\
\hline
\end{tabular}

\begin{tabular}{lll}
\hline Aarhus (1991-2001) & $1.6(1.3-2.5)$ & $0.9(0.43-1.5)$ \\
Reykjavik (1989-2001) & $3.6(3.0-4.9)$ & $2.9(2.0-4.0)$ \\
Bergen (1990-1999) & $3.1(2.7-4.2)$ & $2.3(1.5-3.2)$ \\
Göteborg (1989-1999) & $2.2(2.1-3.6)$ & $1.1(0.58-1.8)$ \\
Umeå (1989-1999) & $2.1(1.8-3.0)$ & $1.0(0.51-1.6)$ \\
Uppsala (1989-1999) & $2.1(1.8-3.1)$ & $1.4(0.89-2.1)$ \\
Tartu (1992-2001) & $0.5(0.2-1.1)$ & $0.3(0.04-1.2)$ \\
\hline
\end{tabular}

Data are presented as incidence rate $(95 \%$ confidence interval $(\mathrm{CI}))$.

attacks, use of asthma medications or self-reported asthma at the start of follow-up. Wheezing and allergic rhinitis were the factors most strongly associated with a subsequent reporting of asthma onset. When, in addition, subjects with wheezing, cough and dyspnoea were excluded, the incidence rate decreased to 1.5 cases $\cdot 1,000$ person-yrs ${ }^{-1}$.

The use of self-reported asthma may introduce misclassification in relation to chronic obstructive pulmonary disease (COPD). This misclassification is age dependent, because COPD mainly occurs after 50 yrs of age. In addition, a sexdependent misclassification has been described previously [14]. The age of the population for this study was 30-54 yrs, which to some extent minimises the misclassification in relation to COPD. In addition, the incidence rate was not increased among the oldest part of the population, an argument against misclassification in relation to COPD.

Self-reported asthma or physician-diagnosed asthma has a high specificity and a low sensitivity [1, 2]. Regarding asthma, the gold standard can be a problematic issue, but mostly the gold standard for asthma has been either clinical investigations, including metacholine challenge tests or a clinical investigation performed by a physician. We have recently validated a sample of subjects responding "yes" and "no" to the question about physician-diagnosed asthma [15]. Taking into account the sampling fraction, the specificity of the item about physician-diagnosed asthma was 0.998 and the sensitivity was 0.36 . Hence, the use of self-reported asthma in epidemiological studies will cause an underdetection of subjects with asthma. It is also reasonable to assume that the false-negatives are subjects with mild asthma, as shown by our preliminary data (unpublished data). In addition to the underreporting by the subjects themselves, there is probably underdiagnosis by the physicians. It has been shown that, in subjects with mild disease, asthma is often overlooked by physicians [16].

The reported year of onset for asthma is sensitive to misclassification, meaning that a subject may report an incorrect year. We are aware of only one other study validating the self-reported year of diagnosis or disease onset among subjects with asthma [15]. In that study, a telephone interview of 32 subjects with physician-diagnosed asthma showed that 14 reported the same year $( \pm 1 \mathrm{yr})$ in the interview and five subjects $(16 \%)$ deviated by $>5$ yrs. The preliminary data from the present study shows 222 subjects reporting year of adult-onset asthma $10 \mathrm{yrs}$ after they received their clinical asthma diagnosis (unpublished data), with $\sim 90 \%$ of the subjects reporting correct year of asthma onset $( \pm 1 \mathrm{yr})$. In the baseline study (part of ECRHS I), the screening questionnaire used only measured current asthma symptoms. Hence, the use of an identical screening questionnaire at follow-up would not have enabled us to detect incident cases that occurred and resolved during the 10 -yr interval.

In this study, the average response rate was $77 \%$, but in total only $60 \%$ of the original population answered both questionnaires. This might introduce bias. Nonresponders were younger males who reported significantly more wheezing than responders in 1990. However, no difference was found in the prevalence of asthma and other respiratory symptoms (other than wheezing) between responders and nonresponders. The increased prevalence of wheezers among nonresponders may decrease the incidence estimates.

The observed incidence rate, 2.2 cases $\cdot 1,000$ person-yrs ${ }^{-1}$, is probably falsely increased because of some misclassification at baseline, i.e. subjects with asthma but not reporting asthma may show up during the follow-up as new-onset asthma. Conversely, the definition of new-onset asthma is based on an operational definition with low sensitivity, i.e. the observed incidence is an underestimation of the true underlying process of asthma onset. The incidence rate of 1.5 cases 1,000 person$\mathrm{yrs}^{-1}$, estimated from a baseline population where subjects reporting different respiratory symptoms have been excluded, is probably largely free from misclassification at baseline, i.e. the estimated incidence is at least not too high. In fact, it may be an underestimation because of the low sensitivity of selfreported asthma. Hence, the incidence rate for asthma is in the range $1.5-2.2$ cases $\cdot 1,000$ person- $\mathrm{yrs}^{-1}$. This incidence range is similar to that reported in other studies [5]. However, some recent longitudinal studies have reported different rates. RÖNMARK et al. [4] from Sweden found an incidence rate of 5 cases $\cdot 1,000$ person-yrs ${ }^{-1}$ among adults; the high incidence may be caused by the higher ages in the sample, 42-73 yrs. In one Canadian study [17], a remarkably high incidence was found, $\sim 6$ cases $\cdot 1,000$ person-yrs ${ }^{-1}$ among males and 12 cases $\cdot 1,000$ person-yrs ${ }^{-1}$ among females, all $25-54$ yrs of age. There is no obvious explanation for these high rates. EAGAN et al. [9], from the Bergen area in Norway, also noted a higher incidence of asthma compared with the currrent study, $\sim 3.5$ cases $\cdot 1,000$ person-yrs ${ }^{-1}$. In that study, only subjects with diagnosed asthma at the start of follow-up were excluded. The incidence rate in the study presented here (with exclusion of subjects with asthma attacks, use of asthma medications or self-reported asthma at start of follow-up) from Bergen was slightly lower, 3.1 cases $\cdot 1,000$ person-yrs ${ }^{-1}$.

As in most other studies, a higher incidence rate was also found for females ( 2.9 cases 1,000 person-yrs $\left.{ }^{-1}\right)$ compared with males $\left(1.5\right.$ cases $\cdot 1,000$ person-yrs $\left.{ }^{-1}\right)$. Different factors, such as airway size, hormonal factor status and socioeconomic factors, have been discussed [18]. The incidence rate may also reflect a tendency among physicians to diagnose an asthma-like disorder as asthma in females and COPD in males [14]. The incidence was independent of age (or birth year), which is in accordance with most other studies in the age span 25-50 yrs [5].

In this data set, reporting of allergic rhinitis at the start of follow-up increased the risk for adult-onset asthma, which is in accordance with other studies [15, 19-21]. Reporting of allergic rhinitis may be considered as a proxy for atopy, with the increased risk only reflecting the influence of atopy.

In this study, an increased risk for asthma during smoking person-years was observed, as in a previous study [5]. The risk was rather low, 1.3, which is probably due to bias, because smokers with respiratory symptoms, such as cough, stop smoking but receive a diagnosis of asthma a few years later. The ex-smokers also had a slightly increased incidence rate. The importance of tobacco smoking for asthma onset among adults is still controversial. Several studies have found an increased risk, as summarised by TORÉN and HERMANSSON [5]. However, several prospective studies have failed to find an 
increased risk for asthma in relation to smoking [3, 6, 22]. To some extent the negative studies can be explained by the "healthy smoker effect", which is more manifest if subjects are only followed for part of their potential smoking time [23]. Negative studies may also be biased, because there is a tendency to label asthma-like disorders as asthma in nonsmokers but not in smokers [24]. Conversely, active smokers seem to have more severe asthma than nonsmokers [25]. This observation is also supported by a case study in which cigarette smoking is associated with more severe asthma [26]. Hence, the use of self-reported asthma may overestimate the asthma risk among smokers, because self-reported asthma probably is biased in relation to disease severity.

The estimated incidences were different between the centres. This may be due to a random effect, but, compared with the other centres, the incidence rate in Iceland was significantly higher and in Estonia it was significantly lower. Among the Swedish centres the variability was low, as the estimated incidence rates were almost identical. Hence, the difference was more associated with country than with centre. The prevalence of current asthma symptoms among the subjects with incident asthma indicated, however, a diagnostic bias. Iceland, with high incidence, had the lowest prevalence of current asthma symptoms, indicating that less severe cases receive a physician's diagnosis of asthma. However, the numbers are low, and this may also reflect random effects. Hence, the present data preclude a definitive answer as to whether these findings reflect different diagnostic traditions or a different underlying true rate of disease onset.

In this prospective, population-based study, the incidence rate of asthma in the whole population ranged 1.5-2.2 cases $\cdot 1,000$ person-yrs ${ }^{-1}$, with a higher incidence range among females. The incidence was dependent on the extent to which subjects with respiratory symptoms were excluded from follow-up. Hence, for comparability between studies, the exclusion criteria in the follow-up population must be stated.

Acknowledgements. The RHINE study group includes: E.J. Jensen (Aarhus); A. Gulsvik, B. Laerum, E. Omenaas, C. Svanes (Bergen); A-C. Olin, K. Torén, A. Tunsäter, L. Lillienberg; A. Dahlman-Höglund (Göteborg); E. Björnsson, T. Gislason, D. Gislason, D. Lúdviksdóttir, T. Blöndal, U.S. Björnsdottir (Reykjavik); R. Jõgi, J. Talvik (Tartu); B. Forsberg, K. Franklin, E. Norrman, M. Söderberg, M-C. Ledin (Umeå); G. Boman, M.I. Gunnbjörnsdóttir, C. Janson, E. Lindberg, D. Norbäck, G. Wieslander, U. SpetzNyström, K. Stenudd Cashelunge, E. Rydén(Uppsala).

\section{References}

1. Torén K, Brisman J, Järvholm B. Asthma and asthma-like symptoms in adults assessed by questionnaires. Chest 1993; 104: 600-608.

2. Pekkanen J, Pearce N. Defining asthma in epidemiological studies. Eur Respir J 1999; 14: 951-957.

3. Troisi RJ, Speizer FE, Rosner B, Trichopoulos D, Willet W. Cigarette smoking and incidence of chronic bronchitis and asthma in women. Chest 1995; 108: 1557-1561.

4. Rönmark E, Lundbäck B, Jönsson E, Jonsson A-C, Lindström M. Incidence of asthma in adults-report from the Obstructive Lung Disease in Northern Sweden Study. Allergy 1997; 52: 1071-1078.

5. Torén K, Hermansson B-A. Incidence rate of adult-onset asthma in relation to age, gender, atopy and smoking-A Swedish population based study of 15,813 adults. Int J Tuberc Lung Dis 1999; 3: 192-197.

6. Basagana X, Sunyer J, Zock J-P, et al. Incidence of asthma and its determinants among adults in Spain. Am J Respir Crit Care Med 2001; 164: 1133-1137.

7. Karjalainen A, Kurppa K, Martikainen R, Klaukka T, Karjalainen J. Work is related to a substantial proportion of adult-onset asthma incidence in the Finnish population. Am $J$ Respir Crit Care Med 2001; 164: 565-568.

8. de Marco R, Locatelli F, Cerveri I, Bugiani M, Marinoni A, Giammanco G. Incidence and remission of asthma: A retrospective study on the natural history of asthma in Italy. J Allergy Clin Immunol 2002; 110: 228-235.

9. Eagan TML, Gulsvik A, Eide GE, Bakke PS. Occupational airborne exposure and the incidence of respiratory symptoms and asthma. Am J Respir Crit Care Med 2002; 166: 933-938.

10. Järvholm B, Brisman J, Torén $\mathrm{K}$. The association between epidemiological measures of the occurrence of asthma. Int J Tuberc Lung Dis 1998; 2: 1029-1036.

11. Janson C, Antó JM, Burney $\mathrm{P}$, et al. The European Community Respiratory Health Survey: what are the main results so far? Eur Respir $J$ 2001; 18: 598-611.

12. Miettinen O. Estimability and estimation in case-referent studies. Am J Epidemiol 1976; 103: 226-235.

13. Rothman KJ, Greeland S. Modern epidemiology. 2nd Edn. Philadelphia, USA, Lippincott-Raven, 1998.

14. Dodge RR, Burrows B. The prevalence and incidence of asthma and asthma-like symptoms in a general population sample. Am Rev Respir Dis 1980; 122: 567-575.

15. Torén K, Olin A-C, Hellgren J, Hermansson B-A. Rhinitis increases the risk for adult-onset asthma - a Swedish population-based case-control study (MAP-study). Respir Med 2002; 96: 635-641.

16. Nathell L, Larsson K, Jensen I. Determinants of undiagnosed asthma. Allergy 2001; 57: 687-693.

17. Stewart W, Brookmeyer R, van Natta M. Estimating age incidence from survey data with adjustments for recall errors. J Clin Epidemiol 1989; 42: 869-875.

18. Chen Y, Dales R, Tang M, Krewski D. Sex-related interactive effect of smoking and household pets on asthma incidence. Eur Respir J 2002; 20: 1162-1166.

19. Redline S, Gold D. Challenges in interpreting gender differences in asthma. Am J Respir Crit Care Med 1994; 150: 1219-1221.

20. Greisner WA, Settipane RJ, Settipane GA. Co-existence of asthma and allergic rhinitis: a 23-year follow-up of college students. Allergy Proc 1998; 19: 185-188.

21. Plaschke PP, Janson C, Norrman E, Björnsson E, Ellbjär S, Järvholm B. Onset and remission of allergic rhinitis and asthma and the relationship with atopic sensitization and smoking. Am J Respir Crit Care Med 2000; 162: 920-924.

22. Guerra S, Sherrill DL, Martinez FD, Barbee RA. Rhinitis as an independent risk factor for adult-onset asthma. $J$ Allergy Clin Immunol 2002; 109: 419-425.

23. Vesterinen E, Kaprio J, Koskenvuo M. Prospective study of asthma in relation to smoking habits among 14,729 adults. Thorax 1988; 43: 534-539.

24. Eisner MD. Smoking and adult asthma. A healthy smoker effect? Am J Respir Crit Care Med 2002; 165: 1566-1567.

25. Svanes C, Omenaas E, Eide GE, Fluge ஜ́, Gulsvik A Hospitalisation for lung disease in early childhood and asthma symptoms in young adults. Respir Med 1998; 92: 1003-1009.

26. Siroux V, Pin I, Oryszczyn MP, Le Moual N, Kauffmann F. Relationships of active smoking to asthma and asthma severity in the EGEA study. Eur Respir J 2000; 15: 470-473. 